\title{
論文
}

\section{Applicability of a Strain-Dependent Constitutive Equation on Flow Properties of a Polymer Solution}

by

\author{
Kunihiro Osaki, Mitsutoshi Fukuda, Shin-ichi Ohta and Michio Kurata \\ (Institute for Chemical Research, Kyoto University, Uji, Kyoto)
}

Applicability of a strain-dependent (S-type) constitutive equation was examined for flow properties of a polystyrene solution in diethyl phthalate. Viscoelastic quantities studied were the relaxation modulus $G(t, s)$, transient stresses at the start and cessation of steady shear flow, and the steady shear viscosity $\eta(\kappa)$. Here $t$ is the time, $s$ is the magnitude of shear, and $\kappa$ is the rate of shear. All these quantities were measured with rheometers of cone-and-plate type. The memory function for the S-type equation was determined from experimental results on $G(t, s)$ and therefrom were calculated the stresses associated with steady shear flow. Calculated results were in good agreement with the observed over whole range of rate of shear investigated. The capability of the S-type equation was compared with that of a rate-dependent (R-type) constitutive equation on the basis of present results and some published results. It was concluded that the S-type equation is very useful in some types of flow including steady shear flow and the type of flow for measurement of relaxation modulus.

\section{高分子溶液に対する歪依存性構成方程式の適用性}

\author{
尾崎 邦宏・福田 三寿・太田 伸一・倉田 道夫*
}

（原稿受理：1974年 8 月12日）

\section{1. 緒}

\section{言}

高分子液体のレオロジ一における構成方程式として, 実際に適 用性の検討されているものの大半は, 一つの方程式

$$
\boldsymbol{\sigma}(t)=\int_{-\infty}^{t} \mu\left(t-t^{\prime}, A\left(t^{\prime} \mid t\right)\right) \boldsymbol{S}\left(t^{\prime}\right) d t^{\prime}
$$

の特殊な形とみなすてとができる1). こてで $\boldsymbol{\sigma}(t)$ は時刻 $t$ 亿お ける余剩応力, $\boldsymbol{S}\left(t^{\prime}\right)$ は $t^{\prime}$ における（ $t$ の状態を基隼とした）歪 テンソルから導かれるテンソルである. また $A\left(t^{\prime} \mid t\right)$ は時刻 $t^{\prime}$ に おける歪速度の不变量あるいは $t^{\prime}$ における歪の不変量（ $t$ を基準 とする）である。それぞれに対応して (1) は歪速度依存性（ある いは簡単に $\mathrm{R}$-形）あるいは歪依存性（ $\mathrm{S}$-形）構成方程式と呼ぶ ことにする。乙の形の方程式は微小歪の極限では線形粘弾性の一 般式に帰着し, また応力測定の時刻 $t$ のほかには唯一つの時刻 $t^{\prime}$ における歪状態を与えれば記憶関数 $\mu$ 与 $t^{\prime}$ における值が決定さ

\footnotetext{
* 京都大学化学研究所宇治市五ヶ庄
}

れるという意味で単純であり, 少くとも比較的小さい変形の場合 には特に重要なものであるということができる。

$\mathrm{R}$-形方程式に関しては非常に多くの研究が発表されており, 記憶関数 $\mu$ としても種々の具体的な形が提案されている. 現在ま でのところ, 定常流および定常流に関連した過渡的流動（定常流 の開始，停止時等）の際の応力-歪関係は， R-形方程式でうまく

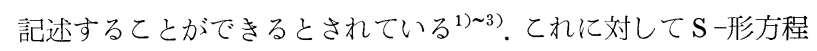
式では，時間に対して不連続的に変化する変形の際の非線形的な 応力挙動（例えば歪依存性緩和弾性率）をも記述し得るという利

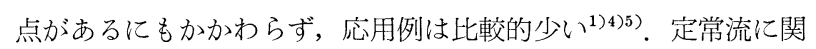
連した過渡的流動や，時間に対して不連続的に変化する変形を含 む種々の変形様式任対する応力-歪関係を統一的に記述する目的 では, むしろ式 (1) より複雑な形の方程式が検討されている ${ }^{32}$.

本研究の目的は, $\mathrm{R}$-形方程式でうまく記述されることになっ ている定常流関係の過渡的応力挙動が， $\mathrm{S}$-形方程式ではどの 程度記述し得るかを調べるととである。同様な研究は Zapas と 
Phillips $^{5)}$ によっても行なわれているが，その研究では記憶関数 祅不充分なデー夕に基づいて直観的に決定されたきらいがある. 本研究では広い範囲の変形量と時間にわたる緩和弾性率の測定值 を基礎にするので，信頼度の高い結論が得られると期待される。

\section{2. 方法}

\section{$2 \cdot 1$ 流動様式之粘弾性関数}

静止していた液体に, 時刻 $t=0$ 以降一定ずり速度 $\kappa$ を加えて, そのときのずり応力と $\kappa$ の比を応力成長関数 $\bar{\eta}(t, \kappa)$ とする

(Fig. 1 b ). 次に 充分長時間定常ずり流動下にあった 液体の流動 を $t=0$ において停止し，その後形を一定に保つときのずり応力 と $\kappa$ の比を応力減衰関数 $\tilde{\eta}(t, \kappa)$ と呼ぶ（Fig. $1 \mathrm{c})$ ．定常ずり粘 度 $\eta(\kappa)$ は

$$
\eta(\kappa)=\lim _{t \rightarrow \infty} \bar{\eta}(t, \kappa)=\tilde{\eta}(0, \kappa)
$$

で与えられる。

静止していた試料に $t=0$ 亿おいて大きさ $s$ のずり歪を加え, その後形を一定に保つときのずり応力と $s$ の比を緩和弾性率 $G(t, s)$ と呼ぶ (Fig. 1 a).
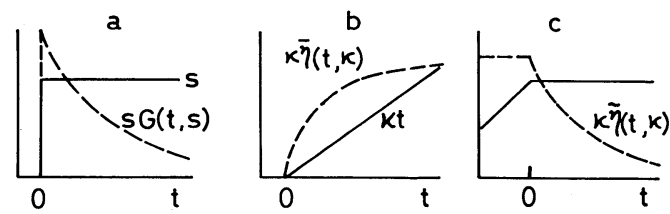

Fig. 1. Types of shear flow examined in this study. Solid and dashed lines represent shear strain and shear stress, respectively. a) One-step strain for measurement of relaxation modulus, b) sudden start of steady shear flow, and c) sudden stop of steady shear flow.

\section{$2 \cdot 2$ S-形方程式の適用}

上に述べたような変形履歴に S - 形方程式を適用すると，次の ような結果が得られる。

$$
\begin{aligned}
& G(t, s)=\sum p f_{p}(s) G_{p} e^{-t / \tau_{p}} \\
& \eta(t, \kappa)=\int_{0}^{t} \sum_{p} G_{p} e^{-t / \tau_{p}}\left[\frac{d s f_{p}(s)}{d s}\right]_{s=\kappa_{\sigma^{\prime}}} d t^{\prime} \\
& \eta(t, \kappa)=\sum p \eta_{p}(\kappa) e^{-t / \tau_{p}} \\
& \eta(\kappa)=\sum_{p} \eta_{p}(\kappa)
\end{aligned}
$$

ただし

$$
\eta_{p}(\kappa)=\left(\frac{G_{p}}{\tau_{p}}\right) \int_{0}^{\infty} f_{p}\left(\kappa t^{\prime}\right) t^{\prime} e^{-t^{\prime} / \tau_{p}} d t^{\prime}
$$

とする. ここで $\tau_{p}, G_{p}(p=1,2,3 \cdots)$ は定数, $f_{p}(s)$ は $s$ の関 数で非線形性を表わすものである，便宜上 $\tau_{1}>\tau_{2}>\tau_{3} \cdots$ とする.

これらの式を実験結果に適用する場合には， $\tau_{1} \gg \tau_{2} \gg \tau_{3} \cdots$ と仮 定して, 線形粘弾性の緩和弾性率 $G(t) \equiv G(t, 0)$ の測定值が再 現されるように $\tau_{p}, G_{p}$ を定め, 次に種々の $s$ の值における $G(t, s)$ の測定值が再現されるように $f_{p}(s)$ を決定する。こてで用いた 仮定は自明なものではないが，結果が良ければ特に否定する必要 はないであろう。

\section{$2 \cdot 3$ 実 験}

分子量分布の狭いポリスチレン（分子量 $3.10 \times 10^{6}$ ) の $15 \%$ フタ ル酸ジチル溶液について, $G(t, s), \bar{\eta}(t, \kappa), \tilde{\eta}(t, \kappa)$, お上び $\eta(\kappa)$ を測定した。 $G(t, s)$ の測定に用いた円錐一円板形応力緩和
計奋7)，およびその他の量の測定に用いた円錐一円板形レオメータ ${ }^{8)}$ については既に報告した。測定は $30^{\circ} \mathrm{C} て ゙$ 行なった。 $s, \kappa, t$ 等の 範囲は Fig. 2-5 に示すとおりである.

\section{3. 結果}

Fig. 2 -5 の実線で示したのは，それぞれ $G(t, s), \tilde{\eta}(t, \kappa), \bar{\eta}$ $(t, \kappa)$ ，および $\eta(\kappa)$ の測定值である。明らかに $G(t, s)$ は $s$ の 増加と共に減少し， $\mathrm{R}$-形方程式では記述し 得ないととがわかる $(\mathrm{R}$ 一形方程式ではずり歪の大きさ $s$ 亿関係なく $G(t, s)=G(t)$ と なる).また $\bar{\eta}(t, \kappa), \tilde{\eta}(t, \kappa)$ ，および $\eta(\kappa)$ は $\kappa$ の増加に伴って 減少する， $\kappa$ の大きいときには， $t$ の関数としての $\bar{\gamma}(t, \kappa)$ には 極大が生じる（ストレス・オーバーシュート）.

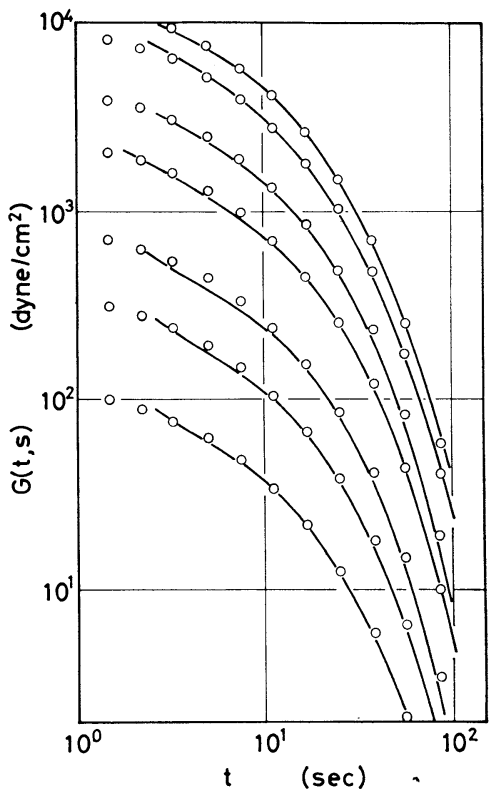

Fig. 2. Strain-dependent relaxation modulus $G(t, s)$ vs. time $t$ for $15 \%$ polystyrene solution in diethyl phthalate. Solid lines represent experimental result and circles represent theoretical values as explained in text. Magnitudes of shear $s$ are 0 , $1.11,3.34,5.52,10.0,15.3$, and 27.2 from top to bottom.

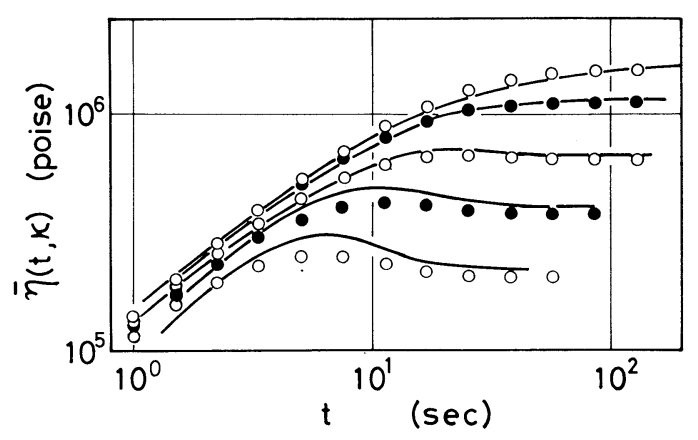

Fig. 3. Stress development function $\bar{\eta}(t, \kappa)$ vs. time $t$ for $15 \%$ polystyrene solution in diethyl phthalate. Solid lines represent experimental result and circles represent theoretical result as explained in text. Rates of shear $\kappa$ are $0,0.0367,0.130,0.272$, and 0.532 from top to bottom. 


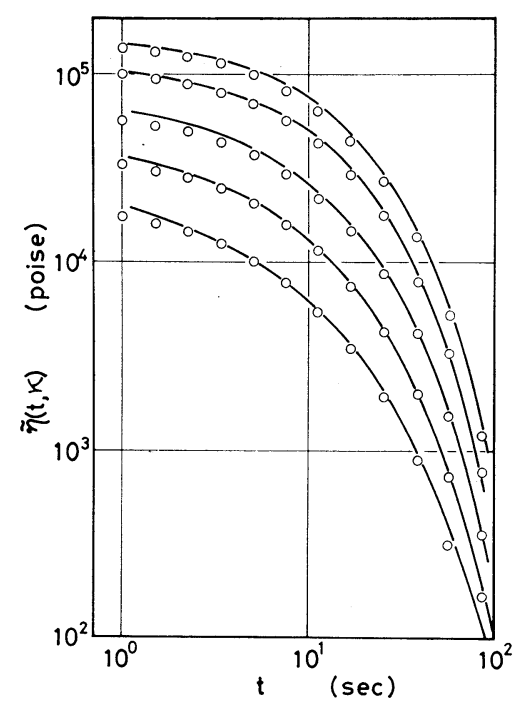

Fig. 4. Stress decay function $\tilde{\eta}(t, \kappa)$ vs. time $t$ for $15 \%$ polystyrene solution in diethyl phthalate. Solid lines represent experimental result and circles represent theoretical result as explained in text. Rates of shear $\kappa$ are $0,0.0367,0.130,0.272$, and 0.532 from top to bottom.

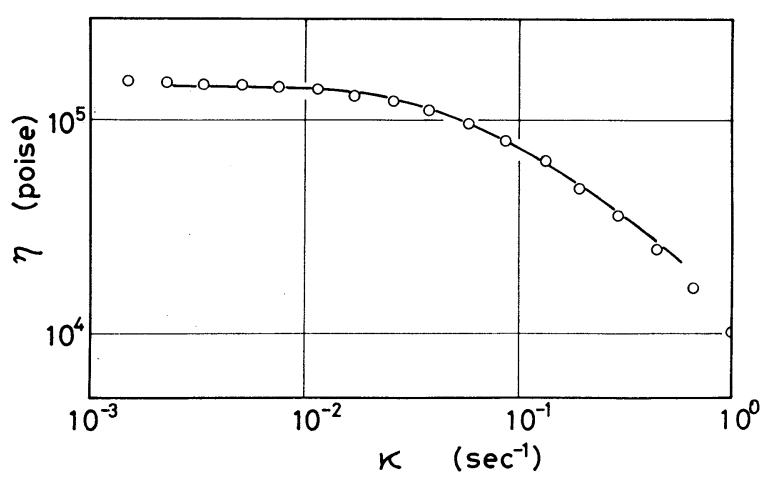

Fig. 5. Steady shear viscosity $\eta(\kappa)$ vs. rate of shear $\kappa$ for $15 \%$ polystyrene solution in diethyl phthalate. Solid line represents experimental result and circles represent theoretical values as explained in text.

図の丸印で示したのは式 (2)一(6) を適用して得られた理論値で ある。 パラメータ $\tau_{p}, G_{p}$ の值を Table 1 亿示す。 てれは Fig. 2 の $s=0$ に対するデータが再現されるように定めたものである. また $f_{p}(s)$ としては

$$
f_{p}(s)=0.913 e^{-0.368 s}+0.087 e^{-0.084 s}
$$

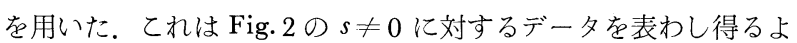
うに定めたものである。 Fig. 2 の $G(t, s)$ のデータは，乙れら の量を用いると式(2)で充分よく近似されているととがわかる，以 上の結果を用いて計算した $\bar{\eta}(t, \kappa), \tilde{\eta}(t, \kappa), \eta(\kappa)$ の理論値は, $\bar{\eta}(t, \kappa)$ の極大付近でわずかに低すぎることを除けば，実験值と よく一致しているということができる.

なお $\tau_{p}, G_{p}(p \geq 2)$ としては Table 1 亿示すものと異なる 值を用いるとともできる。 さらに $f_{p}(s)$ としても式 (7) と関数 形の異なるものを用いるとともできる。いずれの場合にも Fig. 2
Table I. Values of phenomenological parameters $\tau_{p}$ and $G_{p}$

\begin{tabular}{lcccc}
\hline$P$ & 1 & 2 & 3 & 4 \\
\hline$\tau_{p}$ sec & 19.0 & 7.93 & 3.30 & 1.38 \\
$G_{p}$ dyne $/ \mathrm{cm}^{2}$ & 4500 & 6000 & 2000 & 5000 \\
\hline
\end{tabular}

のデータが充分よく再現されるような選び方をした場合には $(t, \kappa), \tilde{\eta}(t, \kappa), \eta(\kappa)$ 等の計算值は Fig. 3-5 亿示す程度に, 実 験值と一致するようである.

\section{4. 考}

\section{察}

\section{$4 \cdot 1$ R-形と S-形方程式の比較}

従来，定常ずり流動に関連した過渡的現象の記述には R-形方 程式の方が適しているのではないかといわれていたが文3，その 根拠について以上の結果と比較しながら検討してみる.

まず， S-形方程式では定常ずり流動開始時における主法線応 力 $\left(\equiv \kappa^{2} \bar{\theta}(t, \kappa)\right.$ とする) のオーバーシュートの出現が予言され ない子言われていたが゙か3)，乙れは主法線応力の測定されていな い試料に対する $G(t, s)$ のデータ ${ }^{9}$ から推論されたもので, 意味 をなさない. 式(7)で表わされる本研究の結果では, 主法線応力の オーバーシュートは予言される。また $\bar{\theta}(t, \kappa)$ の極大になる時間 $t_{N}$ と $\eta(t, \kappa)$ の極大になる時間 $t_{s}$ の間には $t_{N} / t_{S} \leqslant 2$ の関係があ って, 分子量分布の狭い試料では $t_{N} / t_{S} \cong 2$ であるてとが知られ ており ${ }^{2)}$ てれはR-形方程式を用いると, 記憶関数の形に特別の

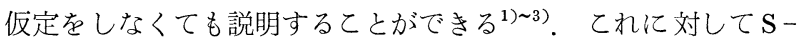
形方程式では，非線形性を表わす関数 $f_{p}(s)$ か $s$ の指数関数に なる場合に限り $t_{N} / t_{S}=2$ という結果が得られる ${ }^{1) 3)}$. 我々の結果 (式(7)）によれば, $f_{p}(s)$ は近似的に単一の指数関数になってい て，乙の条件を満たしているので， $t_{N} / t_{S}$ の值に関する問題は $\mathrm{S}$ 形方程式でも説明するてとが可能ではないかと思われる。

さらに定常ずり流動開始時の応力については van Es とChristensen の研究がある ${ }^{10)}$ 。すなわち $\mathrm{R}$ 一形方程式によれば

$$
\bar{\theta}(t, \kappa)+\int_{0}^{t} \bar{\eta}\left(t^{\prime}, \kappa\right) d t^{\prime}-t \bar{\eta}(t, \kappa)=\int_{0}^{t} t^{\prime} G\left(t^{\prime}\right) d t^{\prime}
$$

が成立するので, 左辺の量は $\kappa$ 亿依存しない単調増加関数でなけ ればならない，実験結果では，乙の量は $\kappa$ の増加と共に減少し， $\kappa$ の非常に大きい場合には，ある $t$ の值において極大になる ${ }^{10)}$. 一方，S-形理論によれば式 (8)の右辺は

$$
\int_{0}^{t} t^{\prime} G^{\prime}\left(t^{\prime}, \kappa t^{\prime}\right) d t^{\prime}
$$

となって, 乙れも $t$ の単調増加関数であるが, $\kappa$ の増加に伴って 減少する。したがって，式(8)の左辺の量が極大をもつてともあ るという実験結果はいずれにしても説明できないが， 数になるという点は S-形方程式によって定性的に説明するてと ができる。

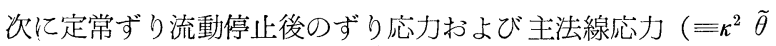
$(t, \kappa)$ とする）については， $\mathrm{R}$-形方程式に基づいて山本の導い た式11

$$
\frac{\partial \theta(t, \kappa)}{\partial t}=-2 \tilde{\eta}(t, \kappa)
$$

が実験結果とよく一致するとされている ${ }^{122)}$. 一方, S-形方程式 
でこれに対応する式は

$$
\frac{\partial \tilde{\theta}(t, \kappa)}{\partial t}=-2 \tilde{\eta}(t, \kappa)\left[1+\frac{\partial \ln \tilde{\eta}(t, \kappa)}{\partial \ln \kappa}\right]
$$

であるが ${ }^{12)}$ ，乙れを式 (10) と比較すると右辺の相対的な差は $\partial \ln \tilde{\eta} / \partial \ln \kappa$ であるてとがわかる. てれは現在の $\partial \tilde{\theta} / \partial t$ の実験 精度から考えて充分誤差の範囲に入り得る大きさであると考えら れる。したがって，現在のとてろ式(10)と(11)の差を実験的に評価す るのは無理であろう。

\section{$4 \cdot 2$ 結 論}

以上の考察から, 本研究の試料を含む一群の高分子溶液に関し て次の結論が得られる。まず，緩和弾性率には歪依存性があって， $\mathrm{R}$-形方程式では記述するてとができない。乙れに対して， S-形 方程式では緩和弾性率のみならず，従来 $\mathrm{R}$-形方程式で記述され ると考えられていた定常ずり流動の開始・停止時の応力も統一的 に記述するてとができる。したがって，てれらの流動様式に関す る限り，もっと一般的な（そして複雑な）構成方程式は必要でな く, また逆に, 乙れらの流動様式に関する研究から, 一般的な方 程式に関する情報を得るととは期待しにくい.さらに，一般的な 構成方程式を求める場合には, 歪の比較的小さい場合に R-形よ りはむしろ S-形方程式に鹵着するものを求めるべきであろう.

本研究を遂行するに当って, 福田を京都大学化学研究所に出向 させて便宜をはかられた東洋曹達工業株式会社に感謝する。

(1974年 5 月 27 日, 日本レオロジー学会第 1 年会にて講演).

\section{文献}

1）例えば，山本三三三，“物体の変形学”，第6，7章（1972）誠 文堂新光社.

2) Sakai, M., H. Fukaya, and M. Nagasawa, Trans. Soc. Rheol., $16: 4,635$ (1972).

3) 高橋雅興, 升田利史郎, 小野木重治, 日本レオロジ一学会誌, 1, 16 (1973).

4) Bernstein, B., E.A. Kearsley, and L.J. Zapas, Trans. Soc. Rheol., 7, 391 (1963) ; 9, 27 (1965).

5) Zapas, L.J., and J.C. Phillips, J. Res. Natl. Bur. Stds., 75A, 33 (1971).

6) Tamura, M., M. Kurata, K. Osaki, Y. Einaga, and S. Kimura, Bull. Inst. Chem. Res., Kyoto Univ., 49, 43 (1971).

7) Einaga, Y., K. Osaki, M. Kurata, S. Kimura, and M. Tamura, Polym. J., 2, 550 (1971).

8) Osaki, K., Y. Einaga, N. Yamada, M. Kurata, and M. Tamura, Polym. J., 6, 72 (1974).

9) Einaga, Y., K. Osaki, M. Kurata, S. Kimura, N. Yamada, and M. Tamura, Polym. J., 5, 91 (1973).

10) van Es, H.E., and R.M. Christensen, Trans. Soc. Rheol., 17, 325 (1973).

11) Yamamoto, M., Trans. Soc. Rheol., 15, 331, 783 (1971).

12）山本三三三，材料，21，355（1972）. 